\title{
The role of energy systems on hydropower in Turkey
}

\author{
Ibrahim Yuksel ${ }^{1, *}$, Hasan Arman ${ }^{2}$, and Ibrahim Halil Demirel ${ }^{3}$ \\ ${ }^{1}$ Yildiz Technical University, Faculty of Civil Engineering, Department of Civil Engineering, \\ Hydraulics Division, 34220 Davutpasa, Istanbul, Turkey \\ ${ }^{2}$ United Arab Emirates University, College of Science, Geology Dep., P.O. 15551, Al-Ain, UAE \\ ${ }^{3}$ Yildiz Technical University, Civil Engineering Ph.D. Student, 34220, Istanbul, Turkey
}

\begin{abstract}
Over the last two decades, global electricity production has more than doubled and electricity demand is rising rapidly around the world as economic development spreads to emerging economies. Not only has electricity demand increased significantly, it is the fastest growing end-use of energy. Therefore, technical, economic and environmental benefits of hydroelectric power make it an important contributor to the future world energy mix, particularly in the developing countries. On the other hand, the hydropower industry is closely linked to both water management and renewable energy production, and so has a unique role to play in contributing to sustainable development in a world where billions of people lack access to safe drinking water and adequate energy supplies. In addition to, approximately 1.6 billion people have no access to electricity and about 1.1 billion are without adequate water supply. However, resources for hydropower development are widely spread around the world. Potential exists in about 150 countries, and about $70 \%$ of the economically feasible potential remains to be developed-mostly in developing countries where the needs are most urgent. This paper deals with renewable energy systems and the role of hydropower in Turkey.
\end{abstract}

\section{Introduction}

Hydropower contributes one-fifth of the world's power generation. In fact, it provides the majority of supply in 55 countries. For several countries, hydropower is the only domestic energy resource. Its present role in electricity generation is therefore substantially greater than any other renewable energy technology, and the remaining potential, especially in the less developed countries such as Turkey, is vast. While it is not a panacea, in that it is restricted to sites with available water and appropriate geomorphology, hydropower's flexibility and proven technology sets it apart from other.

With an estimated $95 \%$ of population growth in the coming decades likely to be in and around cities, the need for sustainable solutions with compact, interconnected power plants will be ever more pressing. Decentralized schemes, however, will remain important for rural electrification programs.

\footnotetext{
*Corresponding author: yukseli2000@yahoo.com or iyuksel@yildiz.edu.tr
} 
Hydropower can be adaptive and flexible. Depending on the storage capacity involved, a major advantage of hydropower is that generation can be scheduled. Run-of-river schemes can be implemented to provide continuous 'base-load' generation. The operation of a cascade of several run-of-river power plants can be optimized to provide generation when it is needed. This is especially true if there is a reservoir scheme at the head of the cascade. Schemes that include a reservoir are able to store potential energy for production when the demand is highest.

When water resources are not available to replenish reservoirs by natural inflow, pumped-storage schemes have been developed to assist in the storage of energy from other generation sources. Therefore, hydropower can substantially improve efficiency in a mixed power system, reducing emissions from fossil-fuel power plants, and backing up intermittent sources such as wind power [1-5].

Hydropower is available in a broad range of project scales and types. Projects can be designed to suit particular needs and specific site conditions. As hydropower does not consume or pollute the water it uses to generate power, it leaves this vital resource available for other uses. At the same time, the revenues generated through electricity sales can finance other infrastructure essential for human welfare. This can include drinking water supply systems, irrigation schemes for food production, infrastructures enhancing navigation, recreational facilities and ecotourism.

Water is a vital resource that supports all forms of life on earth. Unfortunately, it is not evenly distributed by season or geographical region. Some parts of the world are prone to drought, making water a particularly scarce and precious commodity. In other parts of the world, floods that cause loss of life and property are major problems. Throughout history, dams and reservoirs have been used successfully in collecting, storing and managing water needed to sustain civilization. Hydropower often supports other essential water services such as irrigation, flood control and drinking water supplies. It facilitates the equitable sharing of a common vital resource [4-7].

\section{Hydropower and renewable energy for sustainable focus on Turkey}

In view of its geographical location, the mainland of Anatolia has throughout historical times been the birthplace of many great civilizations. It has also been prominent as a centre of commerce because of its connections to three continents and the seas surrounding it on three sides. As a result of the varied geographical conditions, Turkey shows great diversity in geological structure, topography, climate and vegetation. The country is subdivided into seven regions: four of them (Black Sea, Marmara, Aegean, Mediterranean) are coastal units, and the remaining three (Central Anatolia, East Anatolia, Southeast Anatolia) are mountainous and subject to harsh climatic conditions [8].

According to the latest population survey (in 2000), the population of Turkey is 67.80 million of which 44.00 million live in urban settlements and 23.79 million live in rural settlements. The annual population growth rate fell below $2 \%$ for the first time in history after 1945 . The population in urban settlements increases at a rate greater than that in rural settlements. In the last decade, the population in urban settlements has shown a considerable increase, rising from $56 \%$ in 1990 to $64.9 \%$ in 2000 . On the other hand, the average life expectancy in the country is 71.24 years. The infant mortality rate is $4.73 \%$; and the literacy rate is $85 \%$ [8]. 


\section{Water resources}

The amount of precipitation in any particular region usually varies from year to year but, over a long period, the average remains relatively constant. Turkey averages about $643 \mathrm{~mm}$ of precipitation annually, but the distribution is quite uneven. The range is from less than $250 \mathrm{~mm}$ in the inland areas of central Anatolia to more than $3000 \mathrm{~mm}$ in the northeastern Black Sea coastal region. Autumn marks the start of the rainy season, which continues until late spring on the western and southeastern coasts; whereas the Black Sea coast receives rain throughout the year.

This average annual precipitation corresponds to an average of $501 \mathrm{~km}^{3}\left(501\right.$ billion $\left.\mathrm{m}^{3}\right)$ of water per year. While $274 \mathrm{~km}^{3}$ of this quantity returns to the atmosphere through evaporation-transpiration, $69 \mathrm{~km}^{3}$ feeds the aquifers through infiltration from the surface. Thus the average annual surface water potential is $186 \mathrm{~km}^{3}$, of which $158 \mathrm{~km}^{3}$ comes from surface runoff and $28 \mathrm{~km}^{3}$ of groundwater feeds the rivers. With a surface run-off of $7 \mathrm{~km}^{3}$ volume coming from the neighboring countries, the total surface run-off within the country reaches $193 \mathrm{~km}^{3}$. However, from the economic and technical points of view, the average exploitable water potential of the country is $110 \mathrm{~km}^{3}$ per year $[8,9]$.

In view of the considerable variation in runoff in terms of seasons, years and regions, it is absolutely necessary for the major rivers in Turkey to have water storage facilities, to allow for the use of the water when it is necessary. Consequently, priority has always been given to the construction of water-storage facilities. Significant progress has taken place in the construction of dams throughout the 48 years that have elapsed since the establishment of the State Hydraulic Works (DSI) [9]. With the projects developed primarily by DSI and other institutions engaged in water resources development, water consumption in Turkey reached 39.3 billion $\mathrm{m}^{3}$ by 2000 , corresponding to only $36 \%$ of the economically exploitable water resources. During water consumption estimates on a sectoral basis, it is accepted that all of the economically irrigable land will be irrigated with irrigation schemes constructed by the year 2030 and water consumption for irrigation will be 71.5 billion $\mathrm{m}^{3}$. Hence, while its share in the total consumption was $75 \%$ in 1999 , the share of irrigation water in the total water consumption will be decreased to $65 \%$ by the year 2030 , through the utilization of modern irrigation techniques [10].

It has been accepted that the total population of Turkey will reach 110 million by 2030 , with an annual increase rate of $2 \%$. Additionally, it is assumed that the per capita water consumption of $280 \mathrm{l}$ /day (in 2003) will reach 540 1/day by 2030. By taking into consideration that about 5.2 billion $\mathrm{m}^{3}$ water is needed in the tourism sector, the total water consumption for domestic purposes will reach 26.1 billion $\mathrm{m}^{3}$ by 2030 . With the assumption of $4 \%$ annual growth rate in the industrial sector, it is expected that industrial water consumption will increase from 4.8 billion $\mathrm{m}^{3}$ in 2003 to 13.2 billion $\mathrm{m}^{3}$ in 2030 . Thus, considering all of these issues that $100 \%$ of the total economically exploitable water resources will be under use by the year 2030 [7, 11].

The water potential of countries is usually evaluated based on water potential per capita. According to international criteria, countries with a water potential greater than $10,000 \mathrm{~m}^{3}$ per capita per year are accepted as water-rich; countries with a potential of 3,000 to 10,000 $\mathrm{m}^{3}$ are accepted as self-sufficient; countries with a potential of 1,000 to $3,000 \mathrm{~m}^{3}$ are accepted as having a water-deficit; and, those with a water potential of less than $1,000 \mathrm{~m}^{3}$ per capita per year are regarded as water-poor countries [9, 10, 12, 13].

\section{Energy utilization}

The basic target of Turkey's national policy on energy is the provision of cheap electrical energy in sufficient amounts and on time, under qualified, reliable and competing 
conditions of the energy market. The energy policy, determined by 5 -year development plans, is as follows [10]:

- Provision of qualified, reliable and cheap energy for sustainability in socioeconomic development;

- Provision of safety in energy supply;

- Encouragement of private sector investments and expedition of privatization activities in the power sector; and,

- Addition of new and renewable sources as soon as possible to the energy supply cycle.

Studies to maintain power sector competition, increase productivity and provide transparency are going to be carried out to restructure the power sector and establish organizations through the Electricity Market Law [10, 12-14].

\section{Energy resources}

Turkey has a wide variety of conventional and renewable energy resources including lignite, hard coal, asphalted, bituminous shale, oil, natural gas, hydro, biomass, geothermal, wind and solar $[15,16]$. Table 1 shows both current situation and future aspect on renewable energy supply, generation and consumption in Turkey [10, 12]. However, most of these are of inadequate quality and quantity. Each of its coal, geothermal and hydro reserves is estimated to be around $1 \%$ of world reserves, and its oil and natural gas reserves are negligible compared with the world total [10, 12-14, 17]. Turkey's national energy resources consist mainly of hydraulic (126 TWh/year), lignite (105 TWh/year) and hard coal (16 billion $\mathrm{kWh} / \mathrm{year}$ ) resources, with a total annual average of $248 \mathrm{TWh}$. Approximately $126 \mathrm{TWh}$ of hydropower potential corresponds to 35,000 MW of generation capacity. Although $35-46 \%$ of electricity generation was provided by hydropower before 1993 , the share of hydropower decreased to $23 \%$ in $2001[10,12]$.

Table 1. Primary energy supply, generetion and final consuption in Turkey.

\begin{tabular}{|c|c|c|c|c|c|}
\hline Renewable energy sources & $\mathbf{2 0 0 0}$ & $\mathbf{2 0 0 5}$ & $\mathbf{2 0 1 0}$ & $\mathbf{2 0 1 5}$ & $\mathbf{2 0 2 0}$ \\
\hline \multicolumn{2}{|c|}{ Primary energy supply } \\
\hline Hydropower (ktoe) & 2656 & 4067 & 4903 & 7060 & 9419 \\
\hline Geothermal, solar and wind (ktoe) & 978 & 1683 & 2896 & 4242 & 6397 \\
\hline Biomass and waste (ktoe) & 6457 & 5325 & 4416 & 4001 & 3925 \\
\hline Renewable energy production (ktoe) & 10091 & 11074 & 12215 & 15303 & 19741 \\
\hline Share of total domestic production (\%) & 38 & 48 & 33 & 29 & 30 \\
\hline Share of TPES (\%) & 12 & 12 & 10 & 9 & 9 \\
\hline \multicolumn{7}{|c|}{ Generation } \\
\hline Hydropower (GWh) & 30879 & 47287 & 57009 & 82095 & 109524 \\
\hline Geothermal, solar and wind (GWh) & 109 & 490 & 5274 & 7020 & 8766 \\
\hline Renewable energy generation (GWh) & 30988 & 47777 & 62283 & 89115 & 118290 \\
\hline Share of total generation (\%) & 25 & 29 & 26 & 25 & 25 \\
\hline \multicolumn{7}{|c|}{ Total final consumption } \\
\hline Geothermal, solar and wind (ktoe) & 910 & 1385 & 2145 & 3341 & 5346 \\
\hline Biomass and waste (ktoe) & 6457 & 5325 & 4416 & 4001 & 3925 \\
\hline Renewable total consumption (ktoe) & 7367 & 6710 & 6561 & 7342 & 9271 \\
\hline Share of total final consumption (\%) & 12 & 10 & 7 & 6 & 6 \\
\hline
\end{tabular}


Electrical energy consumption is one of the most important indicators of economic development and social welfare. Considering electricity consumption development by sector in Turkey, while the consumption by industry has increased, its share has decreased. During the same period, both consumption and the share increased for both the residential and services sectors; there was not a noticeable change in the transportation sector.

On the other hand, it is important to point out the restructuring policies that are directing the development of new and renewable energy, and giving special emphasis to socio-economical bodies, laws and legal regulations. In this respect, particular attention and priority should be given to the development of the hydroelectric potential in Turkey, since it is the most important natural renewable resource and only $35 \%$ of the technically and economically utilizable hydro potential has been developed so far $[10,12-14,17,18]$.

\section{Hydropower development and review of Turkey}

\subsection{Historical review and situation of the last decades}

Hydroelectric power plants go back some 90 years and they supply about $34 \%$ of the electricity produced in Turkey. The first production began with a $60 \mathrm{~kW}$ hydro plant in Tarsus, which was used only for providing lights during the initial years of the Republic of Turkey. The installed capacity taken over by the Republic was $29,664 \mathrm{~kW}$, and the electricity was available only in Istanbul, Izmir, Tarsus and Adapazarı. With the development of industry, usage of electrical energy other than for lighting started in 1930 and large industrial establishments began trying to produce their own electricity [19-23].

Water projects were initiated by the Ministry of Public Works under the leadership of Atatürk in 1932. The Electrical Power Resources Planning and Survey Administration (EIE) was then established in 1935 to define Turkey's energy demand, carrying out surveys and investigations to develop the hydroelectric potential of water resources and other energy resources. The important projects of that period were: Seyhan, Sariyer, Hirfanl, Kesikköprü, Demirköprü and Kemer dams and hydro plants. There were altogether 28 hydro plants, sharing $3.2 \%$ of the total energy production, by 1940 . Etibank and the Bank of the Provinces were involved in the construction of small hydropower plants and the electrification of villages and towns [21-24].

On the other hand, $85 \%$ of the total hydro capacity in operation has been developed by DSI , corresponding to $9,931 \mathrm{MW}$ (49 hydro plants) and 35,795 GWh/year respectively. The largest and most comprehensive regional development project ever implemented by DSI in Turkey is "The Southeast Anatolian (GAP) Project", which is located in the region of Southeast Anatolia on the Euprates and Tigris Rivers and their tributaries, which originate in Turkey [25-30]. By 2004, 203 small hydro projects (with installed capacities of less than $10 \mathrm{MW}$ ) were at various stages of development. When fully developed, these projects will have a total installed capacity of $849 \mathrm{MW}$ and generate $3623 \mathrm{GWh} /$ year. So far, 70 SHP projects have been put into operation, 6 are under construction and 127 projects are at various planning stages. In other words, $2.4 \%$ of the total economic installed capacity and $3 \%$ of the energy potential correspond to SHP projects (plants of less than $10 \mathrm{MW}$ ) $[9,10,12,30,31]$.

\subsection{Hydropower potential and important of hydropower in Turkey}

It is estimated that there is considerable small hydropower (SHP) potential in Turkey. DSI has started a pre-investigation study on "The Place of Small HEPPs Within Estimated Hydroelectric Potential". These studies conclude that an additional technical hydroelectric 
energy potential of $57 \mathrm{TWh} /$ year could be utilizable. $38 \mathrm{TWh} /$ year of hydroelectric energy potential, corresponding to two-thirds of this additional potential, has been estimated to be economically utilizable, so the total economically utilizable hydroelectric potential of Turkey will reach $164 \mathrm{TWh} /$ year [10, 25, 32-35].

Approximately $50 \%$ of the additional potential of $38 \mathrm{TWh}$ (that is, $19 \mathrm{TWh}$ ) could be realized as small HEPPs (hydroelectric power plants), with installed capacities of less than $10 \mathrm{MW}$. The share of SHP potential in the total, which is $3 \%$ at present, would be $14 \%$. On the other hand, in accordance with the results obtained from the pre-evaluation study, about $15 \%$ of the increase in $126 \mathrm{TWh} /$ year exploitable energy potential might be achieved by developing additional SHP potential. However, this study gives only rough results about the additional SHP potential of the country and the potential must be evaluated more precisely, with comprehensive master plan studies for each hydrological basin [10, 22, 33].

The generation of hydropower provides an alternative to burning fossil fuels or nuclear power, which allows for the power demand to be met without producing heated water, air emissions, ash, or radioactive waste. Of the two alternatives to hydropower, in the last decade, much attention has been given to thermal power production because of the adverse effect of $\mathrm{CO}_{2}$ emissions. With the increasing threat of greenhouse gases originating from such anthropogenic activities on the climate, it was decided to take action. Thus the Framework Convention on Climate Change was enacted on 21 March 1994 and has been signed by 174 countries to date.

Dams that produce electricity by this most productive renewable clean energy source in the world provide an important contribution to the reduction of air pollution. The result of an investigation held in the USA suggests that the productivity of hydroelectric powerplants is higher than $90 \%$ of thermal plants and this figure is twice that of thermal plants. In case of Turkey, the public has been wrongly informed. Some people have claimed that hydro plants do not produce as much energy as planned because of irregular hydrological conditions and rapid sedimentation of reservoirs. It is also claimed that the cost of the removal of dams entirely filled by sediment at the end of their physical lives is not considered in the total project cost, and that there are major problems in recovering the cost of investment and environmental issues [11].

\subsection{Current situation and future aspect in Turkey}

The Ministry of Energy and Natural Resources carries out the general energy planning studies, using an 'MAED' demand model, and TEIAS, (Turkish Electricity Transmission Company) carries out energy generation expansion planning studies, using the DECADES model. The MAED model [10], which was developed by the International Atomic Energy Agency (IAEA), makes projections of the medium and long-term general electricity demand. It takes into consideration a detailed analysis of social, economic and technical systems. The model is based on low, medium and high case scenarios.

The TEIAS, has prepared the Long-Term Energy Generation Plan, taking into consideration the MAED model demand outcome. According to the Plan, the installed capacity will increase to $57,551 \mathrm{MW}$ in 2010 and to $117,240 \mathrm{MW}$ in 2020 . The installed hydropower capacity is anticipated to increase to $18,943 \mathrm{MW}$ in 2010 and to 34,092 MW in 2020. Thus, an additional $1000 \mathrm{MW}$ of hydro capacity should be added to the system annually over the next 20 years. Turkey is thus seeking support for the development of all its economic potential by 2023 , which is the $100^{\text {th }}$ anniversary of the foundation of the Turkish Republic [13, 17, 33]. 


\section{Conclusions}

Turkey's demand for energy is increasing rapidly and heavily dependent on expensive imported energy resources. As would be expected, the rapid expansion of energy production and consumption has brought with it a wide range of environmental issues at the local, regional and global levels. With respect to global environmental issues, Turkey's GHG emissions have grown along with its primary energy consumption. In this regard, renewable energy resources appear to be the one of the most efficient and effective solutions for clean and sustainable energy development in Turkey.

Turkey's geographical location has several advantages for extensive use of most of these renewable energy sources. Turkey has substantial reserves of renewable energy sources, including approximately $1 \%$ of the total world hydropower potential. There is also significant potential for wind power development. Turkey's geothermal potential ranks seventh worldwide, but only a small portion is considered to be economically feasible. This article presents the role of renewables in meeting energy demand of Turkey as a sustainable manner.

Turkey, with its young population and growing energy demand per person, its fast growing urbanization, and its economic development, has been one of the fast growing power markets of the world for the last two decades. Turkey is heavily dependent on expensive imported energy resources that place a big burden on the economy and air pollution is becoming a great environmental concern in the country. In this regard, renewable energy resources appear to be the one of the most efficient and effective solutions for clean and sustainable energy development in Turkey.

On the other hand, renewable energy supply in Turkey is dominated by hydropower and biomass, but environmental and scarcity-of-supply concerns have led to a decline in biomass use, mainly for residential heating. As a contributor of air pollution and deforestation, the share of biomass in the renewable energy share is expected to decrease with the expansion of other renewable energy sources such as solar and wind. There is also significant potential for wind power development. Turkey's geothermal potential ranks seventh worldwide, but only a small portion is considered to be economically feasible. Turkey should be use the renewable energy sources as much as possible to meet the energy demand as a clean and sustainable manner. Of course, the climate change is a reality and country's imported expensive energy demand is increasing rapidly.

\section{References}

1. I. Yuksel, J. of En. So., Part A: Rec., Util., and Env., Eff. 31, 20, 1915-35 (2009)

2. Renew. and Sus. E. Reviw. 12, 1622-40 (2008)

3. K. Kaygusuz, E. Con. and Man. 43, 1099-1120 (2002)

4. K. Kaygusuz, E. S. 26, 215-224 (2004)

5. IEA, International Energy Agency. World Energy Outlook 2002, (2002)

6. IHA. The role of hydropower in sustainable development, www.hydropower.org (2003)

7. WEC. Survey of Energy Resources, www.worldenergy.org (2001)

8. UNDP. World Energy Assessment Report, New York: United Nations (2000)

9. DIE. Statistic yearbook of Turkey in 2003 (Ankara, 2004) 
10. DSI. Statistics on hydropower, www.dsi.gov.tr (2004)

11. WCD. Dams and Development, www.wcd.org (2000)

12. MENR., Ministry of Energy and Natural Resources. 2009. Energy Statistics in Turkey. Available from http://www.enerji.gov.tr.

13. IEA. Energy Policies of IEA Countries: Turkey 2005 Review (2005)

14. IHA. Hydropower information and country report for Turkey, www.hydropower.org (2006)

15. D. Altınbilek, Wa. Res. Dev. 18, 9-24 (2002)

16. O. Yuksek, M.I. Kömürcü, I. Yüksel, K. Kaygusuz, En. Pol. 34, 3093-3103 (2006)

17. TEDAS. www.tedas.gov.tr (2003)

18. TEIAS. Short history of electrical energy development in Turkey. http://www.teias.gov.tr (2005)

19. UNDP/W. B. E. S. Mana. Assi. Prog. (ESMAP). Turkey-Energy and the Environment, Issues and Options Paper. Report 229, (2000)

20. H. Özgöbek, S. Timuçin, DSI, HYDRO conf., Dev., Man., Perf. (2002)

21. F. Adigüzel, A. Tutus, DSI, HYDRO conf., Dev., Man., Perf. (2002)

22. D. Altınbilek, C. Çakmak, DSI, 3rd Inte. Sym., Os. (2001)

23. C. Çakmak, DSI, Report on the Development of Hydroelectric Energy (1998)

24. H.D. Altınbilek, M. Bayram, T. Hazar, Benefits and Concerns about Dams and

Case Studies, 203-212, 67th Annual Meeting of ICOLD (1999)

25. K. Kaygusuz, En. So. 23, 775-799 (2001)

26. K. Kaygusuz, En. So. 24, 803-815 (2002)

27. R. Ozturk, O. Kincay, En. So. 26, 1141-56 (2004)

28. I. Yuksel, J. of En. So., Part B: E., P., and Po. 2, 2,113-21 (2007)

29. I. Yuksel, J. of En. E. \& E. 24, 4-5, 361-70 (2006)

30. H. Ceylan, H.K. Oztürk, Int. J. of Gr. En. 1, 393-406 (2004)

31. D. Altinbilek, Hydroelectric development plans in Turkey, www.dsi.gov.tr/doganyazi.htm (2000)

32. C. Akkaya, Benefits and Concerns about Dams and Case Studies, 113-122, 67 $7^{\text {th }}$ Annual Meeting of ICOLD (1999)

33. K. Kaygusuz, Ren. and Sust. En. Revi. 6, 339-366 (2002)

34. EIE. Hydroelectric Power Activities of the EIE, www.eie.gov.tr (2004)

35. K. Kaygusuz, En. So. 21, 581-588 (1999) 